\title{
Neonatal Amygdala Lesions Lead to Increased Activity of Brain CRF Systems and Hypothalamic-Pituitary-Adrenal Axis of Juvenile Rhesus Monkeys
}

\author{
Jessica Raper, ${ }^{1,3}$ Shannon B.Z. Stephens, ${ }^{1,3}$ Amy Henry, ${ }^{3}$ Trina Villarreal, ${ }^{3}$ Jocelyne Bachevalier, ${ }^{1,3}$ Kim Wallen, ${ }^{1,3}$ \\ and Mar M. Sanchez ${ }^{2,3}$ \\ ${ }^{1}$ Departments of Psychology, and ${ }^{2}$ Psychiatry and Behavioral Sciences, Emory University, Atlanta, Georgia 30322, and ${ }^{3}$ Yerkes National Primate Research \\ Center, Atlanta, Georgia 30329
}

\begin{abstract}
The current study examined the long-term effects of neonatal amygdala (Neo-A) lesions on brain corticotropin-releasing factor (CRF) systems and hypothalamic-pituitary-adrenal (HPA) axis function of male and female prepubertal rhesus monkeys. At 12-months-old, CSF levels of CRF were measured and HPA axis activity was characterized by examining diurnal cortisol rhythm and response to pharmacological challenges. Compared with controls, Neo-A animals showed higher cortisol secretion throughout the day, and Neo-A females also showed higher CRF levels. Hypersecretion of basal cortisol, in conjunction with blunted pituitary-adrenal responses to CRF challenge, suggest HPA axis hyperactivity caused by increased CRF hypothalamic drive leading to downregulation of pituitary CRF receptors in Neo-A animals. This interpretation is supported by the increased CRF CSF levels, suggesting that Neo-A damage resulted in central CRF systems overactivity. Neo-A animals also exhibited enhanced glucocorticoid negative feedback, as reflected by an exaggerated cortisol suppression following dexamethasone administration, indicating an additional effect on glucocorticoid receptor (GR) function. Together these data demonstrate that early amygdala damage alters the typical development of the primate HPA axis resulting in increased rather than decreased activity, presumably via alterations in central CRF and GR systems in neural structures that control its activity. Thus, in contrast to evidence that the amygdala stimulates both CRF and HPA axis systems in the adult, our data suggest an opposite, inhibitory role of the amygdala on the HPA axis during early development, which fits with emerging literature on "developmental switches" in amygdala function and connectivity with other brain areas.
\end{abstract}

Key words: ACTH; cortisol; development; dexamethasone; macaque; sex difference

\section{Introduction}

The hypothalamic-pituitary-adrenal (HPA) axis plays a critical role in homeostasis, with a basal circadian secretory rhythm characterized by a peak in cortisol secretion upon awakening, and a decline across the day with a trough at night (Weitzman et al., 1971; Keller-Wood and Dallman, 1984). Superimposed upon this

Received Jan. 21, 2014; revised June 16, 2014; accepted July 14, 2014.

Author contributions: J.R. and M.M.S. designed research; J.R., S.B.Z.S., A.H., T.V., and M.M.S. performed research; J.R. analyzed data; J.R., J.B., K.W., and M.M.S. wrote the paper.

This work was supported by the National Institute for Mental Health (MH050268 to K.W.). The content is solely the responsibility of the authors and does not necessarily represent the official view of the NIMH, or the National Institutes of Health. The studies were also supported by the Center for Behavioral Neuroscience (NSF IBN 9876754), and the Integrated Training in Psychobiology and Psychopathology Fellowship (NIMH T32 MH732525 to J.R.), as well as the National Center for Research Resources to the Yerkes National Research Center (P51 RR00165; YNRC Base Grant) which is currently supported by the Office of Research Infrastructure Programs/OD P510D11132. The YNPRC is fully accredited by the American for the Assessment and Accreditation of Laboratory Care, International. We thank Casie Lyons, Sara Dicker, Rebecca Roberts, Daniela Sanchez, and Patrick McFarland for their invaluable assistance in pharmacological challenges and animal handling; all members of the Bachevalier Laboratory who have helped with the neuroimaging and surgical procedures on the infant monkeys; and Dr Patrick Roseboom for his expertise and willingness to collaborate on the CRF assay.

The authors declare no competing financial interests.

Correspondence should be addressed to Dr Jessica Raper, Yerkes National Primate Research Center, 954 Gatewood Road Northeast, Atlanta, GA 30329. E-mail: jraper@emory.edu.

DOI:10.1523/JNEUROSCI.0269-14.2014

Copyright $\odot 2014$ the authors $\quad 0270-6474 / 14 / 3411452-09 \$ 15.00 / 0$ basal rhythm is the reactive HPA stress response, critical to respond to threats. The amygdala plays a crucial role coordinating behavioral, autonomic, and neuroendocrine stress responses, via mostly excitatory influences on the hypothalamus and brainstem (Aggleton, 2000). It stimulates the HPA axis through indirect projections to the hypothalamic paraventricular nucleus (PVN), including a disinhibitory pathway via the bed nucleus of the stria terminalis (Feldman et al., 1990; Herman et al., 2003 Freese and Amaral, 2009). PVN stimulation releases corticotropin-releasing factor (CRF) into the portal vasculature, which binds to CRF receptors in the anterior pituitary stimulating the release of adrenocorticotrophic hormone (ACTH), which stimulates the synthesis and release of glucocorticoids by the adrenals (Ulrich-Lai and Herman, 2009). Glucocorticoids inhibit their own release via negative feedback through binding to glucocorticoid receptors (GRs) in the pituitary, PVN, and extrahypothalamic brain regions (Myers et al., 2012).

The amygdala's excitatory influence on the HPA axis stress response has been primarily demonstrated in adult animals, with electrical stimulation increasing secretion of glucocorticoids (Mason, 1959; Redgate and Fahringer, 1973; Ehle et al., 1977) and lesions resulting in blunted HPA axis stress responses (Beaulieu et al., 1986; Feldman et al., 1994; Kalin et al., 2004; Machado and 
Bachevalier, 2008). Yet, its influence on HPA axis basal rhythm and negative feedback, particularly during development, has been less studied with scarce rodent studies suggesting a stimulatory role on basal HPA activity (Allen and Allen, 1975; Regev et al., 2012) and no effects reported following adult primate lesions (Norman and Spies, 1981; Sapolsky et al., 1991; Kalin et al., 2004; Machado and Bachevalier, 2008), or neonatal amygdalectomy (Goursaud et al., 2006). The amygdala's role on central CRF systems has also been poorly documented in primates, with scarce studies reporting reduced CRF levels in CSF and HPA axis stress reactivity following adult bilateral lesions of the central nucleus (CeA; Kalin et al., 2004). Thus, there are significant gaps in our understanding of the role of the primate amygdala on the development of the HPA axis and central CRF systems.

Given that developmental neuropsychiatric disorders, such as Autism spectrum disorder, schizophrenia, and mood disorders exhibit both aberrant amygdala development and dysregulation of CRF and HPA functions (Schumann et al., 2011; Tottenham, 2014), we investigated the effects of neonatal amygdala lesions on macaque CRF/HPA axis development. We previously reported altered diurnal cortisol rhythm in infancy (Raper et al., 2013a) and heightened cortisol stress response as juveniles (Raper et al., 2013b). Here we studied whether the effects of neonatal amygdala lesions on diurnal cortisol persist during the juvenile period, as well as the neurobiological mechanisms that underlie higher-stress reactivity, using central CRF measures and pharmacological challenges to examine pituitary-adrenal and negative-feedback functions.

\section{Materials and Methods}

Subjects. All animals were raised by middle-ranking mothers and lived in large social groups of 50-75 adult females with their juvenile and infant offspring and two breeder males $(38 \times 39 \mathrm{~m}$ indoor/outdoor compounds) at the Yerkes National Primate Research Center (YNPRC) Field Station (Lawrenceville, GA), Emory University. Of the 31 juvenile rhesus monkeys (Macaca mulatta) that were included in the original longitudinal developmental study (Raper et al., 2013a,b), 11 could not be included in the current study due to illnesses or injuries, reducing the sample size to 20 animals for the current studies. At $24.8 \pm 1.2 \mathrm{~d}$ of age, nine animals ( 6 males, 3 females) received neonatal neurotoxic lesions of the amygdala (Neo-A) and eight animals ( 3 males, 5 females) received sham operations (Neo-C). In addition, three animals ( 2 males, 1 female) received the same experimental manipulation given to the Neo-C except for the neuroimaging and surgical procedures and were labeled "behavioral controls" (Neo-BC). Although briefly summarized below, procedures for neuroimaging, surgery, estimation of lesion extent, and mother-infant separations/reunion for surgery and returned to the social group after recovery were described in detail in previous reports (Raper et al., 2013a,b) and were performed at the YNPRC Main Station (Atlanta, GA). For the current study, HPA axis neuroendocrine function, as well as CRF concentrations in CSF, were assessed at 12 months of age. The Animal Care and Use Committee of Emory University approved all procedures, which were performed in accordance with the National Institutes of Health Guide for the Care and Use of Laboratory Animals.

Imaging procedures. On the day of surgery, the infants were removed from their mother, sedated with ketamine hydrochloride $(1 \mathrm{mg} / \mathrm{kg})$ and maintained with isoflurane ( $1-2 \%$ to effect). Their head was secured in a nonferromagnetic stereotaxic apparatus, and two MRI sequences were acquired using a Siemens $3.0 \mathrm{~T} / 90 \mathrm{~cm}$ whole-body scanner and a 3 inch circular surface coil. A high resolution T1-weighted scan [spin-echo sequence, echo time $(\mathrm{TE})=11 \mathrm{~ms}$, repetition time $(\mathrm{TR})=450 \mathrm{~ms}$, contiguous $1 \mathrm{~mm}$ section, $12 \mathrm{~cm}$ field-of-view (FOV), $256 \times 256$ matrix] obtained in the coronal plane was used to determine the coordinates of injection sites in the amygdala. Three additional fluid attenuated inversion recovery (FLAIR) scans (3D T2-weighted fast spoiled gradient-echo sequences, $\mathrm{TE}=2.6 \mathrm{~ms}, \mathrm{TR}=10.2 \mathrm{~ms}, 25 \mathrm{flip}$ angle, $12 \mathrm{~cm} \mathrm{FOV}, 256 \times$
256 matrix) were obtained in the coronal plane at $3.0 \mathrm{~mm}$ (each offset of $1 \mathrm{~mm}$ posteriorly) throughout the brain. These two MRI sequences were repeated 7-10 d after the surgical procedure for Neo-A animals to verify lesion site and extent, whereas Neo-C and Neo-BC animals were just separated from their mothers and placed in an isolette incubator for the same amount of time.

Surgical procedure. All surgical procedures were performed under aseptic conditions, an intravenous drip $(0.45 \%$ dextrose $/ 0.9 \% \mathrm{NaCl})$ was placed to maintain normal hydration, and vital signs (heart rate, respirations, blood pressure, expired $\mathrm{CO}_{2}$ ) were monitored throughout the surgery. Nolvasan solution was used to disinfect the scalp and a local anesthetic (Bupivacaine $0.25 \%$ concentration, $1.5 \mathrm{ml}$ ) was injected subcutaneously along the midline to reduce the pain during skin incision. After the skin and underlying connective tissue were gently displaced laterally, two small craniotomies were made in front of bregma and above the amygdala, and the dura was cut and retracted to expose the brain.

Animals in group Neo-A received injections of ibotenic acid ( $\mathrm{pH} 7.4$, $10 \mathrm{mg} / \mathrm{ml}$ concentration) in six to eight sites within the center of the amygdala using $10 \mu \mathrm{l}$ Hamilton syringes. Needles were lowered simultaneously in both hemispheres and a total of $0.6-0.8 \mu$ l of ibotenic acid was manually injected at a rate of $0.2 \mu \mathrm{l} / \mathrm{min}$. After each injection, a $3 \mathrm{~min}$ waiting period was allotted to minimize neurotoxin spread during needle retractions. Neo-C animals received the same surgical procedures, however, no needles were lowered to avoid the potential risk of brain hemorrhage, and no injections were given.

At the completion of the surgical procedures, the dura was closed with silk sutures, the bone opening was covered with Surgicel NU-KNIT ( $a b-$ sorbable hemostat), and connective tissues and skin were closed. The animal was removed from anesthesia, and placed in a temperaturecontrolled incubator ventilated with oxygen until full recovery from anesthesia. All animals received banamine ( $1 \mathrm{mg} / \mathrm{kg}$ for $3 \mathrm{~d}$ ), dexamethasone $(0.5 \mathrm{mg} / \mathrm{kg}$ for $3 \mathrm{~d}$ ), and antibiotic (rocephin, $25 \mathrm{mg} / \mathrm{kg}$ for $7 \mathrm{~d}$ ) after surgery to prevent pain, edema, and infection, respectively.

The Neo-BC animals were an additional control group, that did not receive the neuroimaging and surgical procedures but all other manipulations were similar to the other two groups, including maternal separation, sedation (ketamine hydrochloride, $1 \mathrm{mg} / \mathrm{kg}$ ), shaving of head and scalp disinfection with Nolvasan Solution, and "postsurgery" medication treatments.

Mother-infant reunions and cross-fostering. The day after surgery, the infants were returned to their mothers and monitored constantly via a secure internet web camera. Most mothers (17 of 20 mothers) immediately retrieved their infants and the infants were observed nursing on the mother that same day. In a few cases, however, infants demonstrated difficulty nursing during the first reunion and the mother-infant pairs had to be separated overnight for a few days to monitor nutrition until the infant was able to nurse on the mother adequately.

In three cases, the mother-infant reunions were unsuccessful despite repeated attempts and in two cases the infants were adopted and raised by another adult female that already had an infant that birth season (Neo-A female and Neo-C male). In one case, an amygdalectomized male, was successfully cross-fostered to a mother that had recently lost her infant.

Mother-infant pairs were reintroduced back into their social groups using a staged introduction procedure. All introductions were monitored closely by researchers and were without incident.

Lesion verification. Estimation of the extent of intended and unintended damage for Neo-A animals was made using presurgical and postsurgical MR images (Málková et al., 2001; Nemanic et al., 2002). The high-resolution T1 images were used to help identify the borders of each structure and lower-resolution FLAIR images were used to identify extent of hypersignals, which were then plotted onto corresponding coronal drawings from a normalized infant rhesus monkey brain (J. Bachevalier, unpublished atlas) using Adobe Photoshop software. Drawings were imported into image analysis program ImageJ (version 1.44) to measure the surface area (in pixels squared) containing hypersignals in the amygdala and in all surrounding structures (entorhinal and perirhinal cortex, and hippocampus). Surface areas measured and the slice thickness (i.e., $1 \mathrm{~mm}$ ) were used to obtain an estimate of volume, and the volume of damage for each structure was then divided by the normal volume of that structure 
Table 1. Intended and unintended damage after neurotoxic lesions of the amygdala

\begin{tabular}{|c|c|c|c|c|c|c|c|c|c|c|c|c|}
\hline \multirow[b]{3}{*}{ Subjects } & \multirow{2}{*}{\multicolumn{4}{|c|}{$\begin{array}{l}\text { Intended damage (\%) } \\
\text { Amygdala }\end{array}$}} & \multicolumn{8}{|c|}{ Unintended damage (\%) } \\
\hline & & & & & \multicolumn{4}{|c|}{ Hippocampus } & \multicolumn{4}{|c|}{ Entorhinal } \\
\hline & Rt & Lf & $x$ & W & $\mathrm{Dt}$ & Lf & $x$ & W & Dt & Lf & $x$ & W \\
\hline 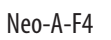 & 90.9 & 0. & 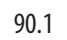 & & 9 & 0.0 & 1.0 & 0.0 & 12.3 & 0.0 & 6.2 & 0.0 \\
\hline & 6 & 58. & 60.0 & 3 & 0 & 0.0 & 0.0 & 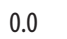 & & 0.0 & 0.8 & 0.0 \\
\hline & 98 & 99. & 98.6 & & 3 & 2.1 & 3.2 & 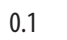 & & .5 & 4.9 & 0.2 \\
\hline Mean & & 82.2 & 82.9 & & & 7 & 1.4 & & .1 & 0.8 & 3.9 & 0.07 \\
\hline $0-A-M 1$ & 100 & & & & & & 9.0 & & 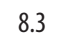 & 15.8 & 12.0 & 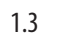 \\
\hline 4 & & & & & & & 0.0 & & & 0.0 & 0 & 0.0 \\
\hline 16 & 77.3 & 92.3 & 84.8 & 71 & 4 & 0.0 & 2.2 & 0. & & 0.3 & 0.2 & 0.0 \\
\hline $0-A-M 7$ & 90.9 & 98.9 & 94.9 & 90.0 & 1 & 0.6 & 2.9 & 0.03 & 1.4 & 0.0 & 0.7 & 0.0 \\
\hline $0-A-M 8$ & 100 & 87.0 & 93.5 & 87.0 & 4 & 0.4 & 3.4 & 0.03 & 7.1 & 0.0 & 3.6 & 0.0 \\
\hline $0-A-M 9$ & 61.8 & 93.2 & 77.5 & 57.6 & 0.0 & 0.0 & 0.0 & 0.0 & 0.0 & 0.7 & 0.4 & 0.0 \\
\hline Mean & 80.1 & 89.5 & 84.8 & 71.6 & 4.1 & 1.7 & 2.9 & 0.14 & 2.8 & 2.8 & 2.8 & 0.22 \\
\hline
\end{tabular}

Rt, Damage in the right hemisphere; $L f$ damage in the left hemisphere: $X$, average damage to both hemispheres: $W$ weighted average damage to both hemispheres ( $\mathrm{W}=\mathrm{Rt} \times \mathrm{Lf} / 100)$; Neo-A-F, female amygdala lesion subject; Neo-A-M, male amygdala lesion subject. Bold numbers represent the average damage for Neo-A females and males. Reprinted with modifications from Raper et al. (2013a), with permission from Elsevier.

(obtained from the template brain in the same manner) and multiplied by 100 to estimate a percentage of the total damage volume.

CSF collection for CRF measures. When the animals reached 12 months of age, a single CSF sample was collected on each subject at sunrise, to match the diurnal timing of HPA axis assessments. Animals were trained to quickly separate from their social group using previously described methods (Sanchez et al., 2010; Raper et al., 2013a,b). Once separated from the social group, animals were immediately anesthetized with Tela$\mathrm{zol}(5 \mathrm{mg} / \mathrm{kg}$, i.m.); the cervical spinal area was shaved, and disinfected with antiseptic solution (betadine) and alcohol. The CSF sample was obtained as soon as possible following anesthesia induction, and within $15 \mathrm{~min}$ from the initial group disturbance. CSF samples were collected from the cisterna magna drawn into a sterile 23-gauge, bevel-tipped needle by pressure difference and collected by gravity (Maestripieri et al., 2006; Sanchez et al., 2007). CSF samples were immediately frozen on dry ice and stored at $-80^{\circ} \mathrm{C}$ until assayed.

HPA axis assessments. At the same age (12 months), a thorough evaluation of long-term effects of neonatal amygdala damage on different aspects of HPA axis function was performed: basal, pituitary-adrenal activity, and glucocorticoid negative feedback. A separate report of stress hyper-reactivity was already published for these amygdalectomized animals at this same age (Raper et al., 2013b).

HPA axis basal activity. Diurnal cortisol secretory rhythm was examined by basal blood samples collected at sunrise, mid-day, and sunset following published protocols (Sanchez et al., 2010; Raper et al., 2013a,b). Briefly, because the animals live outdoors under natural lighting conditions, daylight time was used instead of clock time, and sunrise and sunset times were obtained from the US Naval Observatory (http://aa. usno.navy.mil/data/docs/RS_OneYear.php). Animals were trained to quickly separate from their social group for blood sample collection from the saphenous vein (unanesthetized) within 10 min of initial group disturbance, when experimenters first entered the social group. Blood samples were collected in prechilled $2 \mathrm{ml}$ tubes containing EDTA $(3.6 \mathrm{mg})$ and immediately placed on ice. Samples were centrifuged at $3000 \mathrm{rpm}$ for $15 \mathrm{~min}$ in a refrigerated centrifuge (at $4^{\circ} \mathrm{C}$ ). Plasma was stored at $-80^{\circ} \mathrm{C}$ until assayed.

Pituitary-adrenal function. To assess the functionality of the pituitaryadrenal system, all animals received intravenous injections of either CRF, $\mathrm{ACTH}$, or vehicle (saline) following a counterbalanced design for drug order and with a minimum interval between drug treatments of 1 week. The CRF, ACTH, and corresponding vehicle control intravenous challenges were performed following previously published protocols (Sanchez et al., 2010), and under anesthesia to ensure that animals did not undergo stress-induced HPA axis activations due to repeated handling and venipuncture procedures. Therefore, the results reflect the activation of pituitary-adrenal receptors by the exogenous drugs and the potential effect of the anesthetic was controlled for by the inclusion of the vehicle control intravenous condition in the statistical analyses. Briefly, animals were accessed at sunrise (as described above for the diurnal cortisol assessment), before feeding or other routine care procedures to avoid both meal- or arousal-induced HPA axis activations. Once animals were separated from their social group a baseline blood sample (0 min) was taken by saphenous venipuncture within $10 \mathrm{~min}$ from disturbance, and subjects were immediately anesthetized ( $5 \mathrm{mg}$ telazol $/ \mathrm{kg}, \mathrm{i} . \mathrm{m}$.). An intravenous bolus of $\mathrm{r} / \mathrm{h} \mathrm{CRH}(50 \mu \mathrm{g} / \mathrm{kg}), \mathrm{ACTH}(1 \mu \mathrm{g} / \mathrm{kg})$, or a vehicle solution ( $10 \mathrm{~mm}$ acetic acid/sterile $0.9 \%$ saline) was administered into the saphenous vein opposite to that used to draw blood from the animal, and additional blood samples were collected from the femoral vein at 15, 30, and $45 \mathrm{~min}$ after the injection. Blood samples were collected, processed, and stored as described above for the diurnal samples.

Glucocorticoid negative feedback. Animals were given an intramuscular injection of dexamethasone sodium phosphate $(0.25 \mathrm{mg} / \mathrm{kg})$ at night, $10 \mathrm{~h}$ before sunrise. The day after the dexamethasone injection, blood samples were collected at sunrise to examine the suppression of the early morning cortisol peak secretion and again at mid-day to examine the escape from dexamethasone suppression ( $\sim 16 \mathrm{~h}$ after injection). The sunrise and mid-day samples collected after dexamethasone suppression were statistically compared with the diurnal cortisol samples collected at the same times of the day.

CRF and cortisol assays. CSF samples were assayed for CRF levels by Dr Patrick Roseboom at the University of Wisconsin (Madison, WI). CSF CRF concentrations were measured using an antibody (rC68-5/31/83 bleed) generously provided by Dr Wylie Vale (Salk Institute for Biological Studies, La Jolla, CA). Briefly, the CSF was incubated for $72 \mathrm{~h}$ in the presence of the antibody, followed by a $48 \mathrm{~h}$ incubation with $\left[{ }^{125} \mathrm{I}\right.$ $\left.\mathrm{Tyr}^{0}\right] \mathrm{r}$,hCRH (PerkinElmer). The final dilution of the antibody was $1: 1,000,000$. Following the addition of normal rabbit serum (Bachem) as a carrier, the antigen-antibody complex was pelleted using goat antirabbit gamma globulin $($ Bachem) at $1700 \times g$ for $20 \mathrm{~min}$. The supernatant was removed by aspiration and the radioactivity remaining in the pellet was counted in a gamma counter (PerkinElmer). The amount of $\mathrm{CRF}$ in the sample was determined using a standard curve ranging from 3.91 to $1000 \mathrm{pg} / \mathrm{ml}$ of rat/human, CRF (Sigma-Aldrich). All except three samples were assayed in triplicate with three samples assayed in duplicate due to low sample volume. All samples were processed together in a single CRF assay.

All plasma assays were performed by the YNPRC Biomarker Core Laboratory. Plasma samples for diurnal rhythm, CRF/ACTH/vehicle challenges, and dexamethasone suppression tests were assayed for cortisol. Concentrations of cortisol were assayed in duplicate by radioimmunoassay using commercially available kits (DSL kit, Diagnostic Systems Laboratories). The sensitivity of the DSL assay was $1.25 \mu \mathrm{g} / \mathrm{dl}$ and intraand interassay coefficients of variation in each assay were $<10 \%$.

Statistical analyses. Before examining the effects of neonatal amygdala lesions on our measures, we first performed a preliminary analysis to statistically compare the two subgroups of control animals [i.e., behavioral controls (Neo-BC) and the sham-operated controls (Neo-C)] using repeated-measures ANOVA (control group $\times$ time). Because no significant subgroup (or interaction) effects were found on any of the measures collected, data from both groups were combined to create a single control group referred to as $\mathrm{Neo}-\mathrm{C}$ for all subsequent analyses. Thus, 20 subjects were included in the study (Neo-C: 5 males, 6 females; Neo-A: 6 males, 3 females).

A CSF sample could not be obtained from one Neo-C female within the $15 \mathrm{~min}$ limit and was dropped from analyses. Thus, 19 subjects were included in the final mixed-model ANOVA analysis of CRF levels in CSF (Neo-C: 5 males, 5 females; Neo-A: 6 males, 3 females), with group (Neo-A, Neo-C) and sex (male, female) as fixed factors.

All 20 subjects were included in the analysis of diurnal cortisol rhythm. A preliminary Hierarchical Linear Model (HLM) Regression analysis was performed to rule out effects of "time from disturbance" until collection of blood samples on basal cortisol levels, following previously published protocols (Raper et al., 2013a). Because variance in basal cortisol levels were not significantly explained by the latency to collect the sample $\left(R^{2}\right.$ $\left.=0.15, F_{(1,17)}=1.59, p=0.23\right)$, "time-to-collection" was not used as a covariate in subsequent analyses of group differences in diurnal cortisol. Diurnal cortisol rhythm was analyzed using a repeated-measures 


\section{Neo-C-1 T1-weighted MRI}
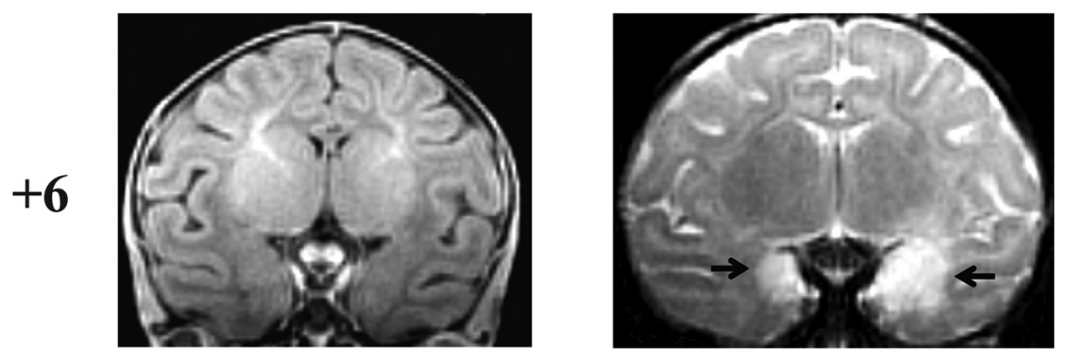

$+5$
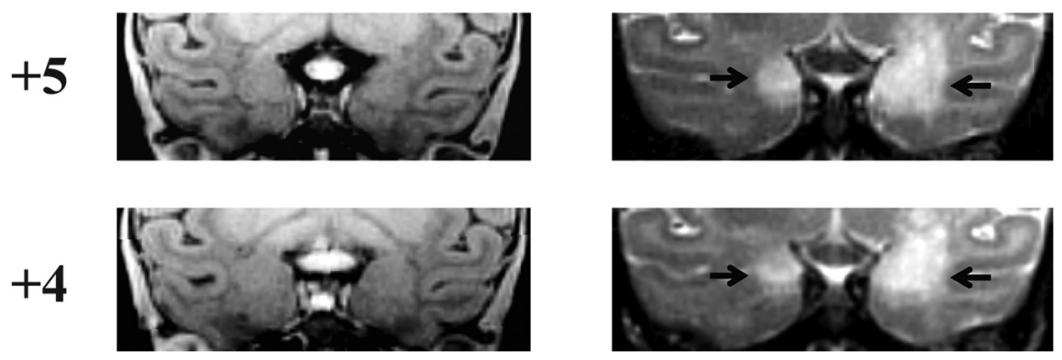

Figure 1. Coronal MRI slices through the amygdala: T1-weighted images in one sham-operated control (Neo-C-M1, left column) and FLAIR (right column) images in a representative case with neonatal amygdala lesions (Neo-A-M1). The numerals to the left of each coronal section indicate the distance in millimeters from the interaural plane. Black arrows point to hypersignals resulting from cell death following neurotoxic injections. Reprinted with modifications from Raper et al. (2013a), with permission from Elsevier.

A

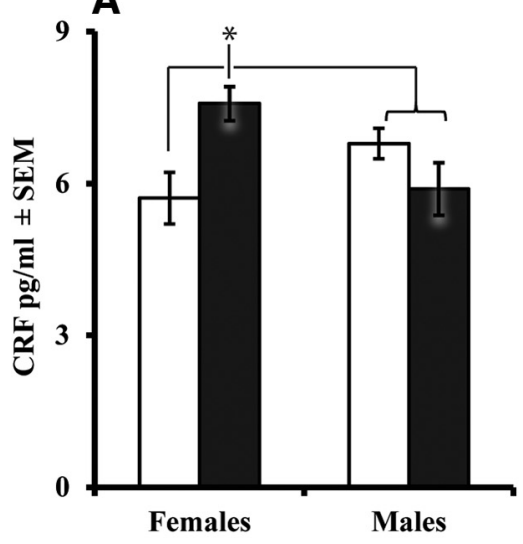

B

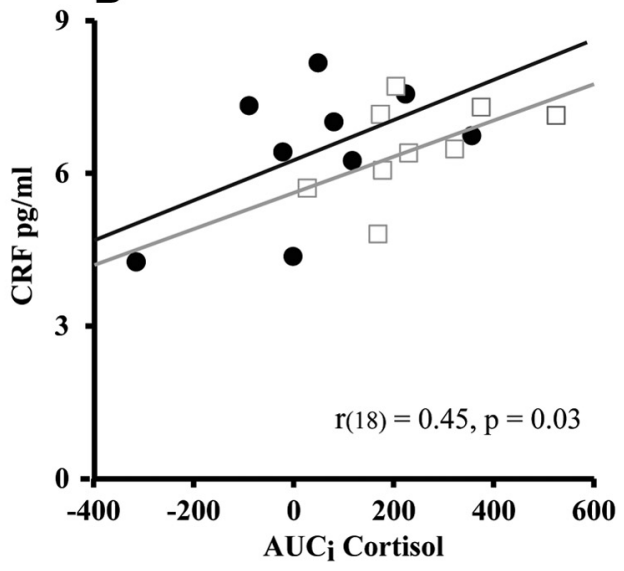

Figure 2. $\quad \boldsymbol{A}$, Mean \pm SEM CRF concentrations in CSF. $\boldsymbol{B}$, Correlation between CRF concentrations in CSF and AUCi cortisol response to a CRF challenge. Neo-C animals are represented by squares or open bars, Neo-A animals are represented by circles or black bars. Black line is the trend line for the $\mathrm{NeO}-\mathrm{A}$ animals and the gray line is the trend line for $\mathrm{NeO}-\mathrm{C}$ animals. ${ }^{*}$ Indicates a significant group difference $(p<0.05)$.

ANOVA with group (Neo-A, Neo-C) and sex (male, female) as fixed factors and time of day (sunrise, mid-day, sunset) as the repeated measure.

One Neo-C female was excluded from the CRF/ACTH/vehicle challenges analyses due to illness (unrelated to the experiment). Another Neo-C female was excluded from the CRF challenge analyses because of incomplete injection of the neuropeptide. Therefore, 18 subjects were included in the final analyses for the $\mathrm{CRF} /$ vehicle challenge analyses (Neo-C: 5 males, 4 females; Neo-A: 6 males, 3 females) and 19 subjects were included in the final ACTH/vehicle analyses (Neo-C: 5 males, 5 females; Neo-A: 6 males, 3 females). Area under the curve with respect to increase (AUCi), which indicates the change in hormones secretions across time with respect to a baseline value, was used to measure the accumulative change in cortisol secretion in response to either CRF,
ACTH, or vehicle injections, from baseline and over time $(0,15,30$, and 45 min postinjection; Pruessner et al., 2003). Mix-design ANOVA with drug (vehicle vs ACTH- or CRF-), group (Neo-A, Neo-C), and sex (male, female) as fixed factors was used to analyze cortisol AUCi responses.

All 20 subjects were included in the analysis of cortisol suppression following dexamethasone injection. A preliminary HLM Regression analysis was conducted to rule out effects of time from disturbance until collection of the blood sample on dexamethasone-induced cortisol suppression, following previously published protocols (Raper et al., 2013a). Because a significant amount of variance in cortisol levels after dexamethasone suppression was explained by the amount of time it took to collect the sample $\left(R^{2}=0.35, F_{(1,17)}=6.33\right.$, $p=0.009)$, time-to-collection was used as a covariate in subsequent analyses of group differences in dexamethasone suppression. Repeated-measures ANOVA included group (Neo-A, Neo-C), sex (male, female), and drug (diurnal/nondrug, dexamethasone) as the fixed factors, time of day (sunrise, mid-day) as the repeating measure, and time to collect the sample as a covariate. We also calculated the escape from dexamethasone suppression as the difference score between the mid-day and sunrise cortisol levels after dexamethasone suppression. This difference score was analyzed using ANCOVA with group (Neo-A, Neo-C) and sex (male, female) as fixed factors and time to collect the sample as a covariate.

Finally, the potential relationship between CRF levels in CSF, AUCi cortisol response to an intravenous CRF challenge, and extent of amygdala damage was investigated using a Pearson product correlation. Two animals were excluded from the analysis because either their CRF levels were not obtained (see above: analysis of CRF in CSF) or because they did not receive the full intravenous $\mathrm{CRF}$ injection (see above: intravenous CRF challenge analysis); thus a total of 18 animals were included in the correlation analyses.

\section{Results}

Lesion extent

Estimated bilateral damage to the amygdala, averaged $83.9 \%$ across both hemispheres (Table 1), but varied from case to case. Thus, substantial bilateral damage to the amygdala in both hemispheres was found in seven cases, averaging 88.5 and $91.5 \%$ on the right and left, respectively. Two other cases had either moderate bilateral damage (Neo-A-F5: right $61.6 \%$, left $58.4 \%$ ) or more asymmetrical amygdala damage (Neo-A-M4: right $50.5 \%$, left $84.9 \%$ ). Unintended damage to surrounding structures was negligible in eight cases, and only one case had moderate damage to the tail of the putamen (Neo-A-F5). Figure 1 illustrates the extent of bilateral amygdala damage in a representative case (Neo-A-M1) as reflected by the location and extent of hypersignals seen in the postsurgical FLAIR images. 


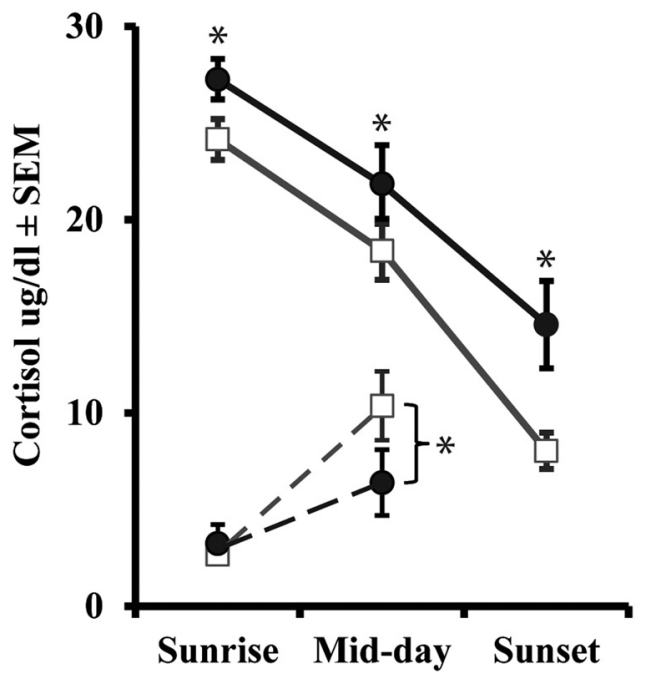

Figure 3. Mean \pm SEM of cortisol across the diurnal rhythm and in response to dexamethasone suppression. Solid lines indicate basal cortisol levels across the diurnal cycle. Dashed lines indicate cortisol levels after dexamethasone administration. All other abbreviations as in Figure 2.

\section{CSF concentrations of CRF}

There was a significant group $\times$ sex interaction for CRF concentrations $\left(F_{(1,19)}=6.5, p=0.022, \eta^{2}\right.$; Fig. $\left.2 A\right)$, with Neo-A females showing higher levels of CRF in CSF compared with Neo-A males and Neo-C animals of both sexes. These results suggest that neonatal amygdala lesions result in central CRF hypersecretion at least in females.

\section{HPA axis assessments}

Basal rhythm

Both amygdala-lesioned and control groups exhibited a significant decline in cortisol secretion across the day (time of day: $F_{(2,32)}=54.21, p<0.001, \eta^{2}=0.77$; Fig. 3), which was linear (repeated contrasts: sunrise vs mid-day $F_{(1,16)}=31.7, p<0.001$, $\eta^{2}=0.67$; mid-day vs sunset $F_{(1,16)}=27.74, p<0.001, \eta^{2}=$ 0.63 ) and followed the species-typical adult-like pattern (Sánchez et al., 2005; Barrett et al., 2009). However, despite similar patterns of daytime cortisol decline, Neo-A animals had significantly higher cortisol secretion compared with $\mathrm{Neo}-\mathrm{C}$ animals throughout the day (group: $F_{(1,16)}=4.78, p=0.044, \eta^{2}=0.23$ ) and this hypersecretion of cortisol did not differ by sex $\left(\operatorname{sex}: F_{(1,16)}=0.92\right.$, $\left.p=0.35, \eta^{2}=0.06\right)$.

Pituitary-adrenal function (CRF and ACTH i.v. administration) As shown in Figure $4 A$, after the ACTH challenge, both groups responded with a significantly increased cortisol compared with a saline injection (drug: $F_{(1,38)}=102.2, p<0.001, \eta^{2}=0.77$ ) and there was no difference between groups or sexes, or significant interactions. Exogenous administration of CRF resulted in a significant increase in cortisol in both groups compared with saline (drug: $F_{(1,36)}=28.4, p<0.001, \eta^{2}=0.50$ ), yet the response was blunted in Neo-A animals compared with controls (group: $F_{(1,36)}$ $=5.42, p=0.027, \eta^{2}=0.16$; Fig. $4 B$ ). There was a significant positive relationship between CRF levels in CSF and AUCi cortisol response to exogenous administration of CRF $\left(r_{(18)}=0.45\right.$, $p=0.03$; Fig. $2 B$ ). There was no relationship between the extent of amygdala damage and either CRF levels or AUCi cortisol response to CRF injection.

Last, glucocorticoid negative feedback was examined using the dexamethasone suppression test. As shown in Figure 3, dexamethasone administration significantly suppressed cortisol levels at sunrise, $10 \mathrm{~h}$ after its administration in both groups, and all animals escaped the glucocorticoid negative feedback by mid-day (drug $\times$ time: $F_{(1,30)}=43.5, p<0.001$, $\left.\eta^{2}=0.59\right)$. Nevertheless, neonatal amygdalectomy altered the effect of dexamethasone suppression (drug $\times$ group: $F_{(1,30)}=$ 4.91, $\left.p=0.035, \eta^{2}=0.14\right)$ with Neo-C animals $(M=7.92 \pm$ $1.4 \mu \mathrm{g} / \mathrm{dl}$ of cortisol) exhibiting a significantly greater escape from dexamethasone suppression than did Neo-A animals $\left(M=2.52 \pm 1.6 \mu \mathrm{g} / \mathrm{dl}\right.$ of cortisol; group: $F_{(1,20)}=6.09, p=$ $\left.0.026, \eta^{2}=0.29\right)$. Therefore, despite basal HPA hyperactivity, $\mathrm{Neo}-\mathrm{A}$ animals show greater glucocorticoid negative feedback than controls.

\section{Discussion}

The present study provides evidence that neonatal amygdala damage alters the normal development of central CRF systems and HPA axis function, leading to long-term effects in prepubertal juvenile monkeys (see Fig. 5 for summary). In contrast to our initial predictions based on adult amygdala lesions, Neo-A animals secreted higher cortisol than controls throughout the day, suggesting that the increased basal HPA activity reported in these animals during infancy (Raper et al., 2013a) persists throughout the juvenile period and parallels their increased stress-induced cortisol reactivity (Raper et al., 2013b). Neonatal lesions also resulted in blunted cortisol responses to CRF administration, indicating downregulation of pituitary CRF receptors as a consequence of hypothalamic CRF hyperactivity. This interpretation is supported, at least in Neo-A females, by their elevated CSF CRF levels. Last, Neo-A animals exhibited an exaggerated cortisol dexamethasone suppression, suggesting increased glucocorticoid negative feedback. Altogether, these results show that early amygdala damage alters the development of CRF and HPA axis systems, and that this brain region plays an inhibitory, rather than stimulatory, role early in life.

Although both groups showed the adult pattern of cortisol decline between early morning, afternoon, and night previously reported in juveniles (Sánchez et al., 2005; Goncharova et al., 2006; Barrett et al., 2009; Collura et al., 2009; Arce et al., 2010), with no effects of Neo-A lesions on daytime cortisol slope, lesioned animals showed elevated cortisol secretions across all time points as compared with controls. Contrary to literature supporting the amygdala's stimulatory role on HPA axis activity (Norman and Spies, 1981; Sapolsky et al., 1991; Herman et al., 2003; Kalin et al., 2004; Machado and Bachevalier, 2008), our findings demonstrate that disruption of the amygdalar inputs to the hypothalamus and other structures regulating the HPA axis during primate neonatal development had a long-term stimulatory effect on basal HPA axis function. Our findings are consistent with recent reports that either CRF knockdown in the CeA or GR knock-out in the BLA result in elevated basal corticosterone secretion (Furay et al., 2008; Regev et al., 2012). Thus, the amygdala could have an inhibitory influence on basal HPA axis activity in both primates and rodents during development, switching later on (in adolescence/adulthood) to be stimulatory. Our findings support an emerging literature on developmental switches of the amygdala's role regulating stress and fear responses. Rodent studies show that the amygdala is functionally dormant before weaning, when the pups are most dependent on maternal care, which is thought to inhibit fear responses toward the mother. This is followed by activation of the amygdala fear/defensive 
A ACTH challenge

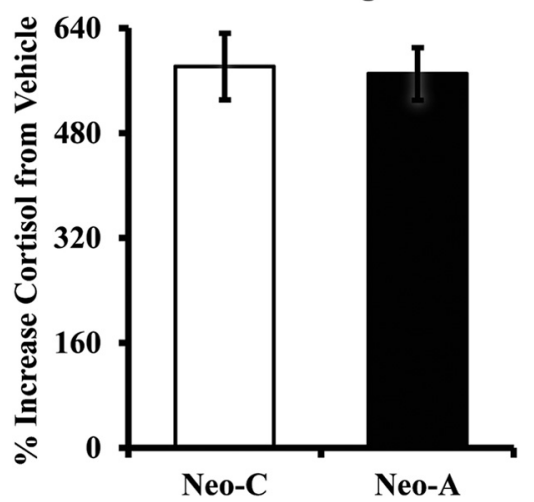

B CRF challenge

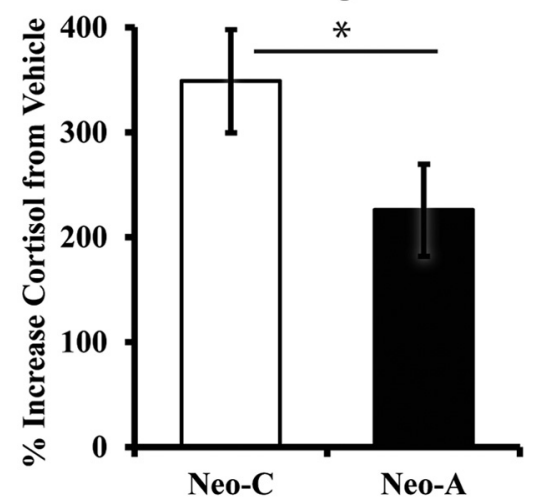

Figure 4. Data represent mean \pm SEM percentage cortisol increase of the AUCi from saline vehicle challenge. $\boldsymbol{A}$, Percentage cortisol increase AUCi of ACTH challenge from vehicle challenge. $\boldsymbol{B}$, Percentage cortisol increase AUCi of CRF challenge from vehicle challenge. All other abbreviations as in Figure 2.

responses coinciding with rising corticosterone levels during the developmental transition to pup independence (after PND 16; Rincón-Cortés and Sullivan, 2014). Developmental switches have also been reported in humans, where amygdala functional connectivity with the medial prefrontal cortex switches from positive coupling during early childhood to negative (adult-like) coupling during the transition to adolescence (Gee et al., 2013b). Interestingly, the functional relevance of this developmental switch from positive to negative coupling has been linked to a transition to stronger emotional regulation. Our findings are consistent with these reports indicating developmental switches in the amygdala's role in emotional and stress regulation.

Early life stress, including adverse caregiving experiences, leads to alterations in HPA axis function (Nemeroff et al., 1984; Sanchez, 2006; Hostinar and Gunnar, 2013). Our findings provide a potential neurobiological mechanism explaining reports of blunted daytime cortisol secretion (Gunnar and Quevedo, 2008), but higher amygdala volumes and activation/reactivity (Tottenham et al., 2010, 2011; Gee et al., 2013a) in some children with early adverse experience. Nonetheless, given that alterations in maternal care have a negative impact on HPA axis development, it remains possible that the elevated cortisol detected in Neo-A juvenile monkeys resulted from alterations in the mother-infant relationship. This seems unlikely given that neither infant attachment to the mother, nor mother-infant interactions were altered in the Neo-A animals (Goursaud et al., 2014; Raper et al., 2014).

To examine the mechanisms underlying the increased HPA basal activity and stress reactivity (Raper et al., 2013b) detected in Neo-A prepubertal juveniles, we measured central CRF levels and used pharmacological challenges to assess pituitary-adrenal function and glucocorticoid negative feedback. Neo-A lesions did not affect cortisol responses to ACTH intravenous administration, suggesting that the differences in basal and stress-induced cortisol secretion are not due to alterations in adrenal cortex responsiveness to ACTH. Animals of both sexes reacted similarly to the ACTH challenge, consistent with reports that sex differences in response to ACTH do not emerge until puberty, when gonadal hormones rise (Meyer and Bowman, 1972; Wilson et al., 2005).

Pituitary-adrenal functioning was further examined by measuring cortisol responses to CRF intravenous injection, which were blunted in Neo-A animals compared with controls. Although this blunted response could be due to an in-

ability to increase cortisol secretion above the already high basal levels, such a potential ceiling effect is unlikely, given that Neo-A animals showed robust cortisol increases in response to stress at the same time of day and age (Raper et al., 2013b). Rather, the blunted cortisol response to CRF suggests downregulation of pituitary CRF receptors in amygdalectomized animals, commonly interpreted as an adaptation to hypersecretion of hypothalamic CRF (Wynn et al., 1985; Hauger and Aguilera, 1993; De Bellis et al., 1994; Heim et al., 2001). This interpretation is supported, at least in Neo-A females, by the elevated CSF CRF levels found in lesioned animals. It is puzzling that Neo-A males did not show elevated CRF levels, despite similar blunted cortisol responses to CRF and increased basal cortisol secretion to Neo-A females. This sex difference in central CRF effects may reflect a long-term physiological adaptation in males, but not females (Heuser et al., 1994; Stroud et al., 2011) or a sexdependent effect of Neo-A damage; future studies need to elucidate these possibilities.

Elevated central CRF levels have been linked to anxiety and emotional dysregulation (Heinrichs and Koob, 2004), with CeA CRF knockdown decreasing and CRF overexpression increasing anxiety-like behavior in rodents (Flandreau et al., 2012; Regev et al., 2012). In monkeys, high CSF CRF levels are also associated with fearful temperament and stressful experiences (Kalin et al., 1983, 2000; Strome et al., 2002; Broadbear, 2006). In this study, although Neo-A animals had elevated CRF levels, they did not exhibit higher emotional reactivity (i.e., freezing, anxiety, or hostility) than controls during a separate study performed at the same age (Raper et al., 2013b). Interestingly, although CSF CRF levels can reflect extrahypothalamic origin, several studies have also demonstrated a link between CSF CRF levels and cortisol levels in blood (Coplan et al., 1996, 2001; Kalin et al., 2004), suggesting a relationship between CSF CRF and HPA function. The significant association found in the current study between CSF CRF levels and the cortisol response to CRF administration provides further support for this link. Therefore, these data suggest that early amygdala damage causes long-term changes in the development of CRF systems, resulting in CRF overactivity and higher HPA axis activity.

Glucocorticoid negative feedback was assessed with the dexamethasone suppression test, with both groups showing cortisol suppression $10 \mathrm{~h}$ after dexamethasone administration in both sexes. The lack of sex difference is likely due to the developmental stage of the animals (juveniles in gonadal quiescence), because sex differences in dexamethasone suppression are influenced by estrogen levels (Heuser et al., 1994; Wilson et al., 2005). The ability of amygdalectomized animals to suppress the morning rise in cortisol in response to dexamethasone indicates that these animals have functional GRs mediating glucocorticoid negative feedback. However, their cortisol escape from dexamethasone suppression later in the day (afternoon) was blunted compared with controls. This dexamethasone super-suppression suggests an increased functionality of GRs in regions that mediate glucocorticoid negative feedback, such as the PFC, hippocampus, or pituitary 
A

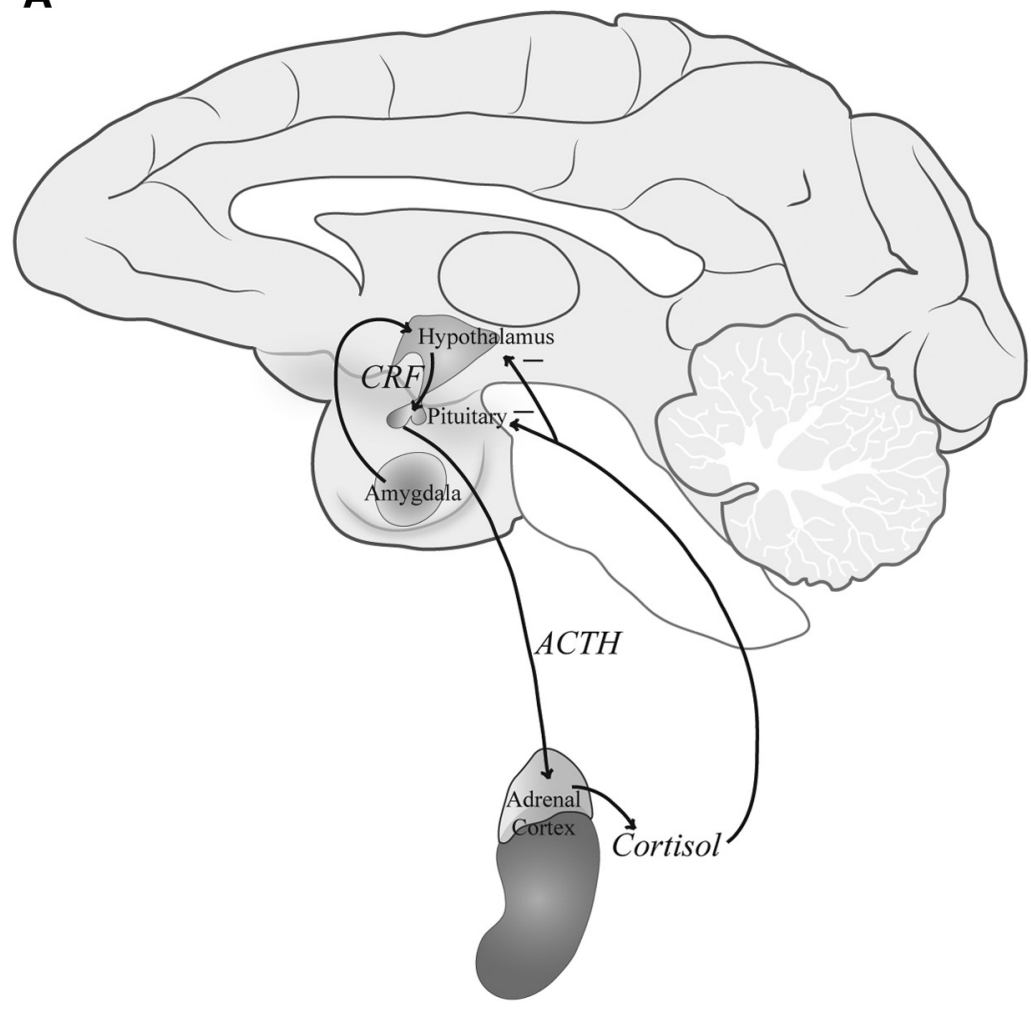

B

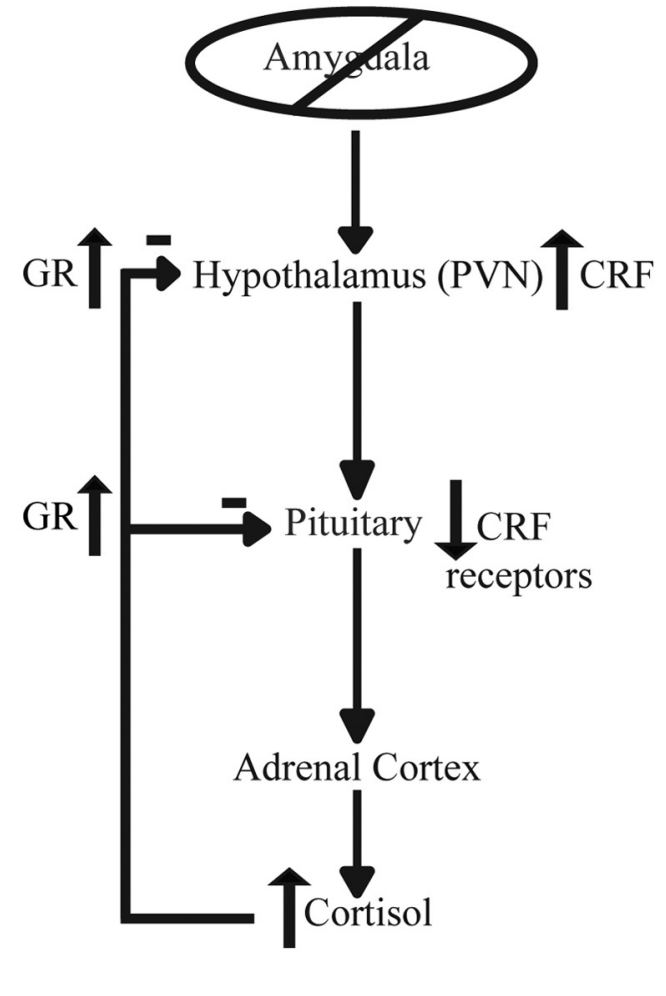

Figure 5. Schematic representation of the impact of neonatal amygdala lesions on the HPA axis during the juvenile period. $\boldsymbol{A}$, Sagittal view of the rhesus monkey brain, illustrating the HPA axis cascade and glucocorticoid negative ( - ) feedback. $\boldsymbol{B}$, proposed mechanisms: early amygdala damage increased ( $\uparrow$ ) CRF and cortisol levels, downregulated ( $\downarrow$ ) CRF receptors at the level of the pituitary, and increased negative feedback on the HPA axis through increased GRs.

(Herman et al., 2003; Myers et al., 2012). These effects of amygdalectomy could be explained by increased GR expression/affinity or altered interactions with chaperone proteins regulated by cortisol (e.g., FKPBP5; Binder, 2009) or other cotransregulators. Although this has been previously reported in clinical conditions that exhibit dexamethasone supersuppression, such as PTSD (Yehuda et al., 2002; van Zuiden et al., 2011), they report hypo-, and not hyper-cortisolemia, making it difficult to fully explain our findings. It is also possible that the changes in glucocorticoid negative feedback reflect direct effects of the lesions on amygdala GRs, whose activation by glucocorticoids, such as dexamethasone have a stimulatory, instead of inhibitory, effect on the HPA axis (Myers et al., 2012). Although many studies underscore the importance of GRs in the hippocampus and PFC in inhibiting the HPA axis (Diorio et al., 1993; Boyle et al., 2005), there is also strong evidence suggesting that amygdaloid GRs can stimulate the HPA axis (Beaulieu et al., 1986, 1987; Shepard et al., 2003; Myers and Greenwood-Van Meerveld, 2011). Therefore, control animals may show escape from dexamethasone suppression through a balance between GRs inhibitory effects and amygdaloid GR activation of the HPA axis, leading to a midday rise in cortisol, whereas amygdalectomized animals that lack amygdaloid GRs show impaired escape.

The amygdala is extensively connected to other brain regions critically involved in the regulation of the HPA axis and central CRF systems, such as the hippocampus and PFC (Aggleton, 2000). These areas are not only rich in GRs but also exhibit a protracted development, like the amygdala (Diorio et al., 1993; Boyle et al., 2005; Payne et al., 2010). Thus, it is possible that early amygdala damage indirectly impacts the
HPA axis and CRF systems by altering the development of the hippocampus and PFC. For example, as reviewed above amygdala-PFC connections are immature during early postnatal development, such that children exhibit a positive coupling between those regions that switches to negative coupling during adolescence (Gee et al., 2013b; Tottenham, 2014), which influences basal cortisol levels (Urry et al., 2006; Veer et al., 2012). Therefore, HPA axis and CRF alterations in Neo-A animals could result from disrupting the normal developmental pattern of amygdala-PFC connectivity, among other possibilities.

Contrary to the expected stimulatory effects of the amygdala based on adult studies, neonatal amygdalectomy resulted in elevated basal cortisol secretion during infancy and the juvenile period, and increased cortisol stress elevations, central CRF levels, and glucocorticoid negative feedback. These findings are of clinical relevance for neuropsychiatric disorders associated with aberrant amygdala development and HPA axis dysregulation, such as Autism spectrum disorder, schizophrenia, and affective disorders (Kaufman et al., 2001; Walker et al., 2008; Corbett et al., 2009; Schumann et al., 2011), and suggest that early amygdala damage alters the development of central CRF and HPA systems resulting in longterm hyperactivity. Our findings represent only the impact of Neo-A lesions during the juvenile prepubertal stage. Additional investigations are underway to determine further changes as the animals reach adolescence and adulthood. Last, future studies will examine whether neonatal lesions impacted other systems, including the hypothalamic-pituitary-gonadal axis, pubertal timing, or metabolism. 


\section{References}

Aggleton JP (2000) The amygdala: a functional analysis. Ed 2. New York: Oxford UP.

Allen JP, Allen CF (1975) Amygdalar participation in tonic ACTH section in the rat. Neuroendocrinology 19:115-125. CrossRef Medline

Arce M, Michopoulos V, Shepard KN, Ha QC, Wilson ME (2010) Diet choice, cortisol reactivity, and emotional feeding in socially housed rhesus monkeys. Physiol Behav 101:446-455. CrossRef Medline

Barrett CE, Noble P, Hanson E, Pine DS, Winslow JT, Nelson EE (2009) Early adverse rearing experiences alter sleep-wake patterns and plasma cortisol levels in juvenile rhesus monkeys. Psychoneuroendocrinology 34:1029-1040. CrossRef Medline

Beaulieu S, Di Paolo T, Barden N (1986) Control of ACTH secretion by the central nucleus of the amygdala: implication of the serotoninergic system and its relevance to the glucocorticoid delayed negative feedback mechanism. Neuroendocrinology 44:247-254. CrossRef Medline

Beaulieu S, Di Paolo T, Côté J, Barden N (1987) Participation of the central amygdaloid nucleus in the response of adrenocorticotropin secretion to immobilization stress: opposing roles of the noradrenergic and dopaminergic systems. Neuroendocrinology 45:37-46. CrossRef Medline

Binder EB (2009) The role of FKBP5, a co-chaperone of the glucocorticoid receptor in the pathogenesis and therapy of affective and anxiety disorders. Psychoneuroendocrinology 34:S186-S195. CrossRef Medline

Boyle MP, Brewer JA, Funatsu M, Wozniak DF, Tsien JZ, Izumi Y, Muglia LJ (2005) Acquired deficit of forebrain glucocorticoid receptor produces depression-like changes in adrenal axis regulation and behavior. Proc Natl Acad Sci U S A 102:473-478. CrossRef Medline

Broadbear JH (2006) Corticotropin-releasing hormone in nonhuman primates. Front Biosci 11:2303-2305. CrossRef Medline

Collura LA, Hoffman JB, Wilson ME (2009) Administration of human leptin differentially affects parameters of cortisol secretion in socially housed female rhesus monkeys. Endocrine 36:530-537. CrossRef Medline

Coplan JD, Andrews MW, Rosenblum LA, Owens MJ, Friedman S, Gorman JM, Nemeroff CB (1996) Persistent elevations of cerebrospinal fluid concentrations of corticotrophin-relesing factor in adult nonhuman primates exposed to early-life stressors: implications for the pathophysiology of mood and anxiety disorders. Proc Natl Acad Sci U S A 93:1619-1623. CrossRef Medline

Coplan JD, Smith EL, Altemus M, Scharf BA, Owens MJ, Nemeroff CB, Gorman JM, Rosenblum LA (2001) Variable foraging demand rearing: sustained elevations in cisternal cerebrospinal fluid corticotrophin releasing factor concentrations in adult primates. Biol Psychiatry 50:200-204. CrossRef Medline

Corbett BA, Schupp CW, Levine S, Mendoza S (2009) Comparing cortisol, stress, and sensory sensitivity in children with autism. Autism Res 2:3949. CrossRef Medline

De Bellis MD, Chrousos GP, Dorn LD, Burke L, Helmers K, Kling MA, Trickett PK, Putnam FW (1994) Hypothalamic-pituitary-adrenal axis dysregulation in sexually abused girls. J Clin Endocrinol Metab 78:249255. CrossRef Medline

Diorio D, Viau V, Meaney MJ (1993) The role of the medial prefrontal cortex (cingulate gyrus) in the regulation of hypothalamic-pituitaryadrenal responses to stress. J Neurosci 13:3839-3847. Medline

Ehle AL, Mason JW, Pennington LL (1977) Plasma growth hormone and cortisol changes following limbic stimulation in conscious monkeys. Neuroendocrinology 23:52-60. CrossRef Medline

Feldman S, Conforti N, Saphier D (1990) The preoptic area and bed nucleus of the stria terminalis are involved in the effects of the amygdala on adrenocortical secretion. Neuroscience 37:775-779. CrossRef Medline

Feldman S, Conforti N, Itzik A, Weidenfeld J (1994) Differential effect of amygdaloid lesions on CRF-41, ACTH and corticosterone responses following neural stimuli. Brain Res 658:21-26. CrossRef Medline

Flandreau EI, Ressler KJ, Owens MJ, Nemeroff CB (2012) Chronic overexpression of corticotropin-releasing factor from the central amygdala produces HPA axis hyperactivity and behavioral anxiety associated with gene-expression changes in the hippocampus and paraventricular nucleus of the hypothalamus. Psychoneuroendocrinology 37:27-38. CrossRef Medline

Freese JL, Amaral DG (2009) Neuroanatomy of the primate amygdala. In: The human amygdala (Whalen PJ, Phelps EA, eds), pp 1-42. New York: Gilford.

Furay AR, Bruestle AE, Herman JP (2008) The role of the forebrain gluco- corticoid receptor in acute and chronic stress. Endocrinology 149:54825490. CrossRef Medline

Gee DG, Gabard-Durnam LJ, Flannery J, Goff B, Humphreys KL, Telzer EH, Hare TA, Bookheimer SY, Tottenham N (2013a) Early developmental emergence of human amygdala-prefrontal connectivity after maternal deprivation. Proc Natl Acad Sci U S A 110:15638-15643. CrossRef Medline

Gee DG, Humphreys KL, Flannery J, Goff B, Telzer EH, Shapiro M, Hare TA, Bookheimer SY, Tottenham N (2013b) A developmental shift from positive to negative connectivity in human amygdala-prefrontal circuitry. J Neurosci 33:4584-4593. CrossRef Medline

Goncharova ND, Shmaliy AV, Bogatyrenko TN, Koltover VK (2006) Correlation between activity of antioxidant enzymes and circadian rhythms of corticosteroids in Macaca mulatta monkeys of different age. Exp Gerontol 41:778-783. CrossRef Medline

Goursaud AP, Mendoza SP, Capitanio JP (2006) Do neonatal bilateral ibotenic acid lesions of the hippocampal formation or of the amygdala impair HPA axis responsiveness and regulation in infant rhesus macaques (Macaca mulatta)? Brain Res 1071:97-104. CrossRef Medline

Goursaud AP, Wallen K, Bachevalier J (2014) Neonatal amygdala lesion and the development of filia attachment in rhesus macaques (Macaca mulatta) raised in a species-typical environment. Dev Psychobiol. Advance online publication. doi: 10.1002/dev.21233. CrossRef Medline

Gunnar MR, Quevedo KM (2008) Early care experiences and HPA axis regulation in children: a mechanism for later trauma vulnerability. In: Progress in brain research, Vol 167 (de Kloet ER, Oitzl MS, Vermetten E, eds), pp 137-149. New York: Elsevier BV.

Hauger RL, Aguilera G (1993) Regulation of pituitary corticotropin releasing hormone $(\mathrm{CRH})$ receptors by $\mathrm{CRH}$ : interaction with vasopressin. Endocrinology 133:1708-1714. CrossRef Medline

Heim C, Newport DJ, Bonsall R, Miller AH, Nemeroff CB (2001) Altered pituitary-adrenal axis responses to provocative challenge tests in adult survivors of childhood abuse. Am J Psychiatry 15:575-581. CrossRef Medline

Heinrichs SC, Koob GF (2004) Corticotropin-releasing factor in brain: a role in activation, arousal, and affect regulation. J Pharmacol Exp Ther 311:427-440. CrossRef Medline

Herman JP, Figueiredo H, Mueller NK, Ulrich-Lai Y, Ostrander MM, Choi DC, Cullinan WE (2003) Central mechanisms of stress integration: hierarchical circuitry controlling hypothalamo-pituitary-adrenocortical responsiveness. Front Neuroendocrinol 24:151-180. CrossRef Medline

Heuser IJ, Gotthardt U, Schweiger U, Schmider J, Lammers CH, Dettling M, Holsboer F (1994) Age-associated changes of pituitary-adrenocortical hormone regulation in humans: importance of gender. Neurobiol Aging 15:227-231. CrossRef Medline

Hostinar CE, Gunnar MR (2013) Future directions in the study of social relationships as regulators of the HPA axis across development. J Clin Child Adolesc Psychol 42:564-575. CrossRef Medline

Kalin NH, Shelton SE, Kraemer GW, McKinney WT (1983) Associated endocrine, physiological and behavioral changes in rhesus monkeys after intravenous corticotropin-releasing factor administration. Peptides 4:211-215. CrossRef Medline

Kalin NH, Shelton SE, Davidson RJ (2000) Cerebrospinal fluid corticotropin-releasing hormone levels are elevated in monkeys with patterns of brain activity associated with fearful temperament. Biol Psychiatry 47:579-585. CrossRef Medline

Kalin NH, Shelton SE, Davidson RJ (2004) The role of the central nucleus of the amygdala in mediating fear and anxiety in the primate. J Neurosci 24:5506-5515. CrossRef Medline

Kaufman J, Martin A, King RA, Charney D (2001) Are child-, adolescent-, and adult-onset depression on and the same disorder? Biol Psychiatry 49:980-1001. CrossRef Medline

Keller-Wood ME, Dallman MF (1984) Corticosteroid inhibition of ACTH secretion. Endocr Rev 5:1-24. CrossRef Medline

Machado CJ, Bachevalier J (2008) Behavioral and hormonal reactivity to threat: effects of selective amygdala, hippocampal, or orbital frontal lesions in monkeys. Psychoneuroendocrinology 33:926-941. CrossRef Medline

Maestripieri D, Higley JD, Lindell SG, Newman TK, McCormack KM, Sanchez MM (2006) Early maternal rejection affects the development of monoaminergic systems and adult abusive parenting in rhesus macaques (Macaca mulatta). Behav Neurosci 120:1017-1024. CrossRef Medline 
Málková L, Lex CK, Mishkin M, Saunders RC (2001) MRI-based evaluation of locus and extent of neurotoxic lesions in monkeys. Hippocampus 11: 361-370. CrossRef Medline

Mason JW (1959) Plasma 17-hydroxycorticosteroid levels during electrical stimulation of the amygdaloid complex in conscious monkeys. Am J Physiol 196:44-48. Medline

Meyer JS, Bowman RE (1972) Rearing experience, stress and adrenocorticoisteroids in the rhesus monkey. Physiol Behav 8:339-343. CrossRef Medline

Myers B, Greenwood-Van Meerveld B (2012) Differential involvement of amygdala corticosteroid receptors in visceral hyperalgesia following acute or repeated stress. Am J Physiol Gastrointest Liver Physiol 302:G260 G266. CrossRef Medline

Myers B, McKlveen JM, Herman JP (2012) Neural regulation of the stress response: the many faces of feedback. Cell Mol Neurobiol 32:683-694. CrossRef Medline

Nemanic S, Alvarado MC, Price RE, Jackson EF, Bachevalier J (2002) Assessment of locus and extent of neurotoxic lesions in monkeys using neuroimaging techniques: a replication. J Neurosci Methods 121:199209. CrossRef Medline

Nemeroff CB, Widerlöv E, Bissette G, Walléus H, Karlsson I, Eklund K, Kilts CD, Loosen PT, Vale W (1984) Elevated concentrations of CSF corticotropin-releasing factor-like immunoreactivity in depressed patients. Science 226:1342-1344. CrossRef Medline

Norman RL, Spies HG (1981) Brain lesions in infant female rhesus monkeys: effects on menarche and first ovulation and on diurnal rhythms of prolactin and cortisol. Endocrinology 108:1723-1729. CrossRef Medline

Payne C, Machado CJ, Bliwise NG, Bachevalier J (2010) Maturation of the hippocampal formation and amygdala in Macaca mulatta: a volumetric magnetic resonance imaging study. Hippocampus 20:922-935. CrossRef Medline

Pruessner JC, Kirschbaum C, Meinlschmid G, Hellhammer DH (2003) Two formulas for computation of the area under the curve represent measures of total hormone concentration versus time-dependent change. Psychoneuroendocrinology 28:916-931. CrossRef Medline

Raper J, Bachevalier J, Wallen K, Sanchez M (2013a) Neonatal amygdala lesions alter basal cortisol levels in infant rhesus monkeys. Psychoneuroendocrinology 38:818-829. CrossRef Medline

Raper J, Wallen K, Sanchez MM, Stephens SB, Henry A, Villareal T, Bachevalier J (2013b) Sex-dependent role of the amygdala in the development of emotional reactivity to threatening stimuli in infant rhesus monkeys. Horm Behav 63:646-658. CrossRef Medline

Raper J, Stephens SBZ, Sanchez M, Bachevalier J, Wallen K (2014) Neonatal amygdala lesions alter mother-infant interactions in rhesus monkeys living in a species-typical social environment. Dev Psychobiol. Advance online publication. doi:10.1002/dev.21234. CrossRef Medline

Redgate ES, Fahringer EE (1973) A comparison of the pituitary adrenal activity elicited by electrical stimulation of preoptic, amygdaloid and hypothalamic sites in the rat brain. Neuroendocrinology 12:334-343. CrossRef Medline

Regev L, Tsoory M, Gil S, Chen A (2012) Site-specific genetic manipulation of amygdala corticotropin-releasing factor reveals its imperative role in mediating behavioral response to challenge. Biol Psychiatry 71:317-326. CrossRef Medline

Rincón-Cortés M, Sullivan RM (2014) Early life trauma and attachment: immediate and enduring effects on neurobehavioral and stress axis development. Front Endocrinol 5:1-15. CrossRef Medline

Sanchez MM (2006) The impact of early adverse care on HPA axis development: nonhuman primate models. Horm Behav 50:623-631. CrossRef Medline

Sánchez MM, Noble PM, Lyon CK, Plotsky PM, Davis M, Nemeroff CB, Winslow JT (2005) Alterations in diurnal cortisol rhythm and acoustic startle response in nonhuman primates with adverse rearing. Biol Psychiatry 57:373-381. CrossRef Medline

Sanchez MM, Alagbe O, Felger JC, Zhang J, Graff AP, Maestripieri D, Miller AH (2007) Activated p38 MAPK is associated with decreased CSF 5-HIAA and increased maternal rejection during infancy in rhesus monkeys. Mol Psychiatry 12:895-897. CrossRef Medline

Sanchez MM, McCormack K, Grand AP, Fulks R, Graff A, Maestripieri D
(2010) Effects of sex and early maternal abuse on adrenocorticotropin hormone and cortisol responses to the corticotrophin-releasing hormone challenge during the first 3 years of life in group-living rhesus monkeys. Dev Psychopathol 22:45-53. CrossRef Medline

Sapolsky RM, Zola-Morgan S, Squire LR (1991) Inhibition of glucocorticoid secretion by the hippocampal formation in the primate. J Neurosci 11:3695-3704. Medline

Schumann CM, Bauman MD, Amaral DG (2011) Abnormal structure or function of the amygdala is a common component of neurodevelopmental disorders. Neuropsychologia 49:745-759. CrossRef Medline

Shepard JD, Barron KW, Myers DA (2003) Stereotaxic localization of corticosterone to the amygdala enhances hypothalamopituitary-adrenal responses to behavioral stress. Brain Res 963:203-213. CrossRef Medline

Strome EM, Wheler GH, Higley JD, Loriaux DL, Suomi SJ, Doudet DJ (2002) Intracerebroventricular corticotropin-releasing factor increases limbic glucose metabolism and has social context-dependent behavioral effects in nonhuman primates. Proc Natl Acad Sci U S A 99:15749-15754. CrossRef Medline

Stroud LR, Papadonatos GD, Williamson DE, Dahl RE (2011) Sex differences in cortisol response to corticotropin releasing hormone challenge over puberty: Pittsburgh pediatric neurobehavioral studies. Psychoneuroendocrinology 36:1226-1238. CrossRef Medline

Tottenham N (2014) The importance of early experiences for neuroaffective development. Curr Top Behav Neurosci 16:109-129. CrossRef Medline

Tottenham N, Hare TA, Quinn BT, McCarry TW, Nurse M, Gilhooly T, Millner A, Galvan A, Davidson MC, Eigsti IM, Thomas KM, Freed PJ, Booma ES, Gunnar MR, Altemus M, Aronson J, Casey BJ (2010) Prolonged institutional rearing is associated with atypically large amygdala volume and difficulties in emotion regulation. Dev Sci 13:46-61. CrossRef Medline

Tottenham N, Hare TA, Millner A, Gilhooly T, Zevin JD, Casey BJ (2011) Elevated amygdala responses to faces following early deprivation. Dev Sci 14:190-204. CrossRef Medline

Ulrich-Lai YM, Herman JP (2009) Neural regulation of endocrine and autonomic stress responses. Nat Rev Neurosci 10:397-409. CrossRef Medline

Urry HL, van Reekum CM, Johnstone T, Kalin NH, Thurow ME, Schaefer HS, Jackson CA, Frye CJ, Greischar LL, Alexander AL, Davidson RJ (2006) Amygdala and ventromedial prefrontal cortex are inversely coupled during regulation of negative affect and predict the diurnal pattern of cortisol secretion among older adults. J Neurosci 26:4415-4425. CrossRef Medline

van Zuiden M, Geuze E, Willemen HL, Vermetten E, Maas M, Heijnen CJ, Kavelaars A (2011) Pre-existing high glucocorticoid receptor number predicting development of posttraumatic stress symptoms after military deployment. Am J Psychiatry 168:89-96. CrossRef Medline

Veer IM, Oei NYL, Spinhoven P, van Buchem MA, Elzinga BM, Rombouts SA (2012) Endogenous cortisol is associated with functional connectivity between the amygdala and medial prefrontal cortex. Psychoneuroendocrinology 37:1039-1047. CrossRef Medline

Walker E, Mittal V, Tessner K (2008) Stress and the hypothalamic pituitary adrenal axis in the developmental course of schizophrenia. Annu Rev Clin Psychol 4:189-216. CrossRef Medline

Weitzman ED, Fukushima D, Nogeire C, Roffwarg H, Gallagher TF, Hellman L (1971) Twenty-four hour pattern of the episodic secretion of cortisol in normal subjects. J Clin Endocrinol Metab 33:14-22. CrossRef Medline

Wilson ME, Legendre A, Pazol K, Fisher J, Chikazawa K (2005) Gonadal steroid modulation of the limbic-hypothalamic-pituitary-adrenal (LHPA) axis is influenced by social status in female rhesus monkeys. Endocrine 26:89-97. CrossRef Medline

Wynn PC, Harwood JP, Catt KJ, Aguilera G (1985) Regulation of corticotrophin-releasing factor $(\mathrm{CRF})$ receptors in the rat pituitary gland: effects of adrenalectomy on CRF receptors and corticotroph responses. Endocrinology 116:1653-1659. CrossRef Medline

Yehuda R, Halligan SL, Grossman R, Golier JA, Wong C (2002) The cortisol and glucocorticoid receptor response to low dose dexamethasone administration in aging combat veterans and holocaust survivors with and without posttraumatic stress disorder. Biol Psychiatry 52:393-403. CrossRef Medline 